\title{
Расина Э.О.
}

\section{Место виртуального образа личности в перцептивных процессах социального взаимодействия в виртуальном пространстве}

Крымский инженерно-педагогический университет имени Февзи Якубова, переулок Учебный, д. 8, г. Симферополь, 295015, Республика Крым, Россия rasina.evelina@mail.ru

\section{Статья поступила 29 апреля 2021; принята 10 июня 2021; опубликована 30 июня 2021}

\begin{abstract}
Аннотация. Платформы для социального взаимодействия в сети Интернет оказывают значительное влияние на процессы восприятия и социального познания пользователей. Эффективность межличностного взаимодействия обусловлена особенностями наглядно-образного отражения субъектами друг друга. В момент взаимодействия перед субъектом находится не сам пользователь, а только его семантическое отражение, наполненный символами, сигналами образ реальной личности, который содержит информацию о нем и выполняет функцию транслятора и инструмента управления впечатлением. Виртуальный образ личности рассматривается как источник информации о носителе-пользователе. Восприятие происходит через призму опыта субъекта, который воспринимает образ. Осознается его смыслообразующая функция путем обобщения и интерпретации семантических компонентов. Происходит формирование представления о том или ином человеке путем социальной перцепции, в котором активно принимают участие механизмы социального познания. Цель статьи - в определении места виртуального образа личности в процессах межличностного восприятия в ходе социального взаимодействия в виртуальном пространстве, а также в выявлении особенностей социальной перцепции в виртуальном пространстве в сравнении с процессами реального пространства. Методология $u$ методbl: Исследование проводилось в реальном и виртуальном пространствах. На этапе констатирующего эксперимента для определения психологических особенностей восприятия образа личности в реальном и виртуальном пространстве в качестве психодиагностической методики был использован Тест М. Куна и Т. Макпартленда «Кто Я?» или «20 высказываний» в модификации Т.В. Румянцевой. Анализ результатов проводился путем контент-анализа. Статистический анализ экспериментальных данных был осуществлен с использованием программного обеспечения «SPSS 23.0» (критерий КолмогороваСмирнова, U-критерий Манна - Уитни). Результатьл: Процессы социального восприятия субъектами межличностного взаимодействия в реальном и виртуальном пространствах имеют ряд отличий. Существенные отличия были отмечены в восприятии отдельных компонентов образа личности. Исследование позволило выделить новый, не характерный для реального пространства структурный компонент образа личности - виртуальное Я, которое характеризуется высокой степенью виртуализации деятельности личности (взаимодействия с
\end{abstract}


другими, самоактуализации, самоидентификации) и принятием виртуального пространства как полноценной среды для существования.

Ключевые слова: виртуальный образ личности; социальная перцепция; механизмы социальной перцепции; социальная сеть; аттракция; стереотипизация; идентификация; рефлексия; каузальная атрибуция.

Информация для цитирования: Расина Э.О. Место виртуального образа личности в перцептивных процессах социального взаимодействия в виртуальном пространстве // Научный результат. Педагогика и психология образования. 2021. T.7. №2. C. 115-129. DOI: 10.18413/2313-8971-2021-7-2-0-9.

\title{
E.O. Rasina (iD) $\quad$ The place of the virtual image of the individual in the perceptual processes of social interaction in virtual space
}

Fevzi Yakubov Crimean Engineering and Pedagogical University, 8 Uchebny Ln., Simferopol, Republic of Crimea, 295015, Russia rasina.evelina@mail.ru

Received on April 29, 2021; accepted on June 10, 2021; published on June 30, 2021

\begin{abstract}
Social interaction platforms on the Internet have a significant impact on the perception processes and users' social cognition. The interpersonal interaction effectiveness is due to the peculiarities of the visual-figurative reflection of the subjects of each other. At the interaction moment the subject is not the user himself/ herself, but only his/ her semantic reflection, the real personal image filled with symbols and signals, which contains information about him/ her and performs the translator function and the impression managing tool. The personal virtual image is considered as a source of information about the carrier-user. Perception occurs primarily through the prism of the personal experience who perceives the image. Its meaning-forming function is realized by means of generalization and semantic components interpretation. An idea about a particular person through social perception is formed, in which the social cognition mechanisms are actively involved. The main purpose of this article is to determine the personal virtual image place in the interpersonal perception processes in the social interaction act in the virtual space, as well as to identify the features of social perception in virtual space in comparison with the processes of real space. Methodology and methods: The research was carried out in real and virtual spaces. At the stage of the ascertaining experiment, the "Who am I?" test of M. Kuhn and T. McPartland was used as a psychodiagnostic technique to determine the psychological characteristics of the personality image perception in real and virtual space or "20 statements" as modified by T.V. Rumyantseva. The analysis of the results was carried out by means of content analysis. Statistical analysis of the experimental data was carried out using the SPSS 23.0 software (Kolmogorov-Smirnov test, Mann-Whitney U-test). Results: Analysis of the research data showed that the social perception processes by subjects of interpersonal interaction in real and virtual spaces have a number of differences. Significant differences were noted in the perception of the personality image individual components. The study made it possible to identify a new personality image structural component that is not characteristic of
\end{abstract}


real space - the virtual Self, which is characterized by a high degree of personality's activity virtualization (interaction with others, self-actualization, self-identification) and the acceptance of virtual space as a full-fledged environment for existence.

Keywords: virtual personality image; social perception; social perception mechanisms; social network; attraction; stereotyping; identification; reflection; causal attribution.

Information for citation: Rasina E.O. (2021), "The place of the virtual image of the individual in the perceptual processes of social interaction in virtual space", Research Result. Pedagogy and Psychology of Education, 7 (2), 115-129, DOI: 10.18413/2313-8971-2021-7-2-0-9.

Введение (Introduction). XXI век является переходным этапом от индустриального общества к информационному, что открывает широкие возможности для социального взаимодействия в виртуальном пространстве Интернета. Подобного рода взаимодействия строго локализованы виртуальными платформами, социальными сетями, форумами, сайтами, видеохостингами и т.д. Знакомство между субъектами, таким образом, происходит через восприятие доступных характеристик. Вся доступная информация служит для формирования в сознании пользователя виртуального образа личности, с которой он готов вступить в коммуникацию. Виртуальное пространство диктует новые законы социальной коммуникации, во главе которых становится социальная перцепция, играющая важнейшую роль в современном виртуальном взаимодействии. Исследование новых форм и закономерностей социальной перцепции в виртуальном пространстве тесно связано с виртуальным образом личности, который конструируется пользователями в Интернете.

Основная часть (Main Part). В coвременной науке довольно актуальной проблема в определении места виртуального образа личности в межличностном взаимодействии на просторах виртуального мира. Данный этап в изучении виртуального образа личности позволит продвинуться в исследовании как психологических особенностей, так и функциональных характеристик, и закономерностей данного феномена.

Целью статьи является определение места виртуального образа личности в про- цессах межличностного восприятия в ходе социального взаимодействия в виртуальном пространстве, а также выявление особенностей социальной перцепции в виртуальном пространстве в сравнении с процессами реального пространства.

Для достижения поставленной цели необходимо решить следующие задачи:

- проанализировать теоретические основы социальной перцепции в отечественной и зарубежной науке;

- выявить связь между процессами социальной перцепции и виртуальным образом личности;

- рассмотреть особенности социальной перцепции в виртуальном пространстве;

- выявить психологические особенности межличностного восприятия в виртуальной среде и определить место виртуального образа личности в процессах социальной перцепции в виртуальном пространстве по сравнению с реальным пространством.

Гипотеза исследования - процессы социальной перцепции в реальном и виртуальном мире имеют отличительные черты, которые обусловлены спецификой виртуальной среды. Следует ожидать, что восприятие виртуального образа личности проявляется в различном понимании и интерпретации отдельных компонентов виртуального образа, связанных с законами и механизмами, которые участвуют в регулировании социального взаимодействия в сети Интернет, которые придают процессу перцепции специфический характер и имеют 
характеристики не схожие с подобными в реальном пространстве.

\section{Теоретическая} основа (The theoretical basis). Социальная перцепция это процесс восприятия социальных объектов, социальных групп и общностей. Она является одним из важнейших компонентов общения. Социальная перцепция включает также формирование представления о намерениях, мыслях, способностях, установках другого человека (Андреева, 2001).

Изучая социальное взаимодействие в виртуальном пространстве, необходимо рассмотреть характерные черты межличностного восприятия, так как в выстраивании социального взаимодействия в Интернете именно восприятие человека человеком играет решающую роль.

Межличностная перцепция довольно сложный и многомерный феномен. Он заключает в себе как восприятие физических, так и поведенческих черт партнера.

Шерри Теркл считает, что отношения с компьютером, как посредником между реальным и виртуальным миром, могут в значительной степени изменять представления людей о себе, своей деятельности, профессии, работе, о своих отношениях с другими людьми и о социальных процессах в целом. Подобные процессы становятся основой для формирования новых эстетических ценностей, социальных ритуалов, новой философии и культуры в целом (Turkle, 2015). Следует отметить значительность таких изменений в культурной, мировоззренческой и ценностно-смысловой сферах человеческой активности, что влияет на структурирование информации, процесс считывания и расшифровки семантического содержания образа личности.

В виртуальном пространстве Интернета восприятие человека человеком происходит посредством виртуального образа личности, который конструируется каждым пользователем для участия в социальном взаимодействии в виртуальном пространстве.

Виртуальный образ личности - это намеренная, осознаваемая или частично осознаваемая личностью виртуальная ментальная конструкция, отражающая личностные характеристики носителя, основной функцией которой является создание определенного впечатления у других виртуальных пользователей (Расина, 2019).

Значительную роль в оценке виртуального образа личности играют когнитивные психические процессы, которые способствуют абстрагированию, анализу, синтезу полученных данных (мышление), организованной и целенаправленной селективности признаков (внимание), сопоставлению, полученной информации с прошлым опытом и уже сформировавшимися эталонами (память, воображение, представление), а также интерпретацию информации, которая заложена в образе в виде знаков, символов и шаблонов (паттернов).

Социальная перцепция, как процесс восприятия, имеет в своей основе анализ и обработку стимулов, воздействующих на анализаторы. Современные информационные технологии в значительной мере расширили спектр данных стимулов. Перцепция как одна из форм сенсорного воспроизведения способствует формированию цельного образа в сознании пользователя. При этом на формирование образа может влиять как сила стимулов, так и эмоциональное состояние пользователя, и ситуация взаимодействия.

Таким образом, особое значение в социальном познании в ситуации межличностного взаимодействия играет первое впечатление. Символьное содержание образа личности определяет первое впечатление и эмоциональное отношение к субъекту взаимодействия (Бодалев, 1965). Таким образом, при изучении особенностей социальной перцепции следует уделить внимание, прежде всего, первичному восприятию субъектами друг друга.

Социальная перцепция происходит на двух уровнях: психофизическом и психологическом. Происходит процесс объективации психологических качеств личности, соединение внутреннего (психологического) содержания с внешним знаково- 
символьным (Панферов, 1992). Бодалев А.А. описывал данный процесс через отражение признаков-сигналов, которые в ходе обработки запускают актуализацию в сознании прошлого подобного опыта, привязанного к данному сигналу. При этом семантические компоненты, образующие внешний вид и выразительное поведение довольно разнообразны и в своей совокупности выступают носителями определенной информации, выполняя роль сигналов-стимулов. Первичный образ формируется путем анализа изображения, который представляет собой совокупность отражений реального облика субъекта (Бодалев, 1965).

В процессе взаимопознания участников взаимодействия часто происходит объединение внешних стимулов, например, черт лица, и определенных психологических характеристик. Отражение характерных черт лица человека интерпретируется партнерами по взаимодействию как характеристика внешне неопределяемых качеств личности. Довольно часто можно встретить такие характеристики, как умный лоб, злые глаза, волевой подбородок. Таким образом, происходит объективирование психологических характеристик личности во внешних чертах и выразительных компонентах внешнего вида человека (Панферов, 2009).

В процессе межличностного восприятия в реальном пространстве субъекты взаимодействия оценивают друг друга на основе внешнего вида, вербального и невербального компонентов. Виртуальное пространство формирует новые законы социального взаимодействия и «познания человека человеком».

В процессе социальной перцепции в виртуальном пространстве Интернета некоторые отечественные ученые выделяют в качестве решающего компонента визуальное восприятие другого человека. Восприятие его внешних признаков, анализ и соотнесение их с возможными личностными характеристиками и интерпретацию его поступков и мыслей (Обыденкова, 2012). Другие считают, что важную роль в социальной перцепции в виртуальном пространстве иг- рает вербальный аспект восприятия, в частности текстовая информация и только в незначительной мере визуальная (Войскунский, 2014). Современные социальные сети стремительно развиваются, подстраиваются под запросы современного технического мира. На данный момент большая часть виртуальных платформ может представить широкие возможности для всестороннего восприятия, как вербального, так и визуального компонентов. Кроме этого, социальные сети позволяют ознакомиться с музыкальными предпочтениями своих пользователей, их интересами, принадлежностью к сообществам, недавними взаимодействиями с другими пользователями. Данные возможности позволяют пользователям конструировать собственный виртуальный образ и представлять его другим субъектам, возможным партнерам по взаимодействию.

A.Е. Войкунский в своих работах отмечает, что социальная перцепция участников виртуального взаимодействия в социальных сетях опирается на самопрезентации партнеров по коммуникации (Войскунский, 2014). Самопрезентация - одна из основных функций виртуального образа личности, который демонстрирует основные внешние, социальные и психологические характеристики пользователя.

В виртуальном пространстве субъекты имеют возможность оценивать готовый образ, созданный собеседником. Таким образом, физический компонент социальной перцепции изменяется, и предметом восприятия становится образ. Невербальный же компонент, включающий мимику, жесты и эмоции в виртуальном пространстве отсутствует. Физические характеристики личности воспринимаются через фотообразы, фиксированные изображения в лучшем ракурсе. Исследования показали, что выбор фотоизображения отражает личность пользователя и опирается на впечатление, которое носитель образа хочет произвести на других. Пользователь подбирает определенный тип аватарки, юзерпика, который вызывает симпатию у большинства пользователей (Wu, Chang, Yuan, 2015). 
В ходе социальной перцепции в межличностном взаимодействии можно выделить механизмы, направленные на восприятие внешнего облика и поведения субъекта, и механизмы восприятия внутреннего мира субъекта - социально-психологические характеристики (Фомиченко, 2017).

Среди механизмов внутренних психологических характеристик личности выделяют аттракцию, идентификацию, каузальная атрибуцию, рефлексию, стереотипизацию и эмпатию.

Виртуальный образ личности, как инструмент, направленный на управление впечатлением, играет важную роль в формировании привлекательности виртуальной личности, за которой скрывается реальный человек. Механизм аттракции в социальной перцепции строится на возникновении устойчивого положительного чувства (Гозман,1987). Согласно исследованиям, лица незнакомых субъектов вызывают устойчивое чувство симпатии в случае неоднократной встречаемости (Miller, Perlman, Brehm, 2006). Современные социальные сети регулярно предлагают своим пользователям возможных знакомых, таким образом формируя эффект простого попадания в поле зрения. Подобные выводы были также сделаны после проведения эксперимента Р. Морленда и С. Бич (Moreland, Beach, 1992).

Важную роль в механизме аттракции играет сходство между субъектами. Причем межличностное сходство определятся не только в физическом диапазоне, но и в социально-психологическом. Таким образом, при выявлении степени сходства субъектами учитывается сходство интересов другого человека, музыкальных и литературных предпочтений, принадлежности к той или иной социальной группе (Folkes, 1982). Структура профиля в социальной сети позволяет провести подобного рода сравнение. Кроме этого сеть сама проводить данное строение и предлагает своим пользователям подборку профилей со схожими интересами.

Еще одним важным фактором в формировании межличностной аттракции игра- ет физическая привлекательность. Красивые люди имеют более высокий социальный статус и популярность среди других людей (Walster, Walster, Berscheid, Dion, 1971). Coциальные сети предоставляют своим пользователям ряд широких возможностей не только для демонстрации лучших фото, но и для редактирования и наложения эффектов на изображения.

Механизм идентификации формируется на основе интуитивного соотнесения личности с воспринимаемым субъектом по ряду признаков. Данный механизм чаще всего реализуется путем сравнения субъектом себя с другим пользователем (Обыденкова, 2012).

Стандартизированная структура формирования виртуального образа в социальной сети упрощает процесс идентификации себя с другим человеком. Значительная часть внешнего слоя виртуального образа личности уже будет сопоставима с обликом другого пользователя. Эмоциональная сторона идентификации в данном случае в значительной степени упрощается до рационального анализа структурных компонентов композиции виртуального образа личности.

Идентификация тесно связана с механизмом рефлексии. Данный механизм формируется на основе необходимости субъекта сформировать свой образ с точки зрения других людей. Таким образом, формируется еще один слой виртуального образа личности - «то, как меня видят другие». Социальная сеть «ВКонтакте» позволяет осуществить демонстрацию своего профиля с точки зрения еще не знакомого пользователя и пользователя, уже причисленного к числу «друзей». Такая демонстрация позволяет оценить сконструированный внешний образ с точки зрения других субъектов.

Шестикомпонентная структура перцептивного процесса, в которой участвуют две личности, два представления личности о самом себе и два представления о личности глазами другой личности, также упрощается (Андреева, 2001). Разрыв между тем, что личность о себе представляет и тем, что видят другие пользователи сокращается. Од- 
нако стоит отметить, что профиль в социальной сети представляет только часть виртуального образа личности. Образ, сформированный при анализе профиля, может быть скорректирован и уточнен при дальнейшем коммуникативном взаимодействии.

Каузальная атрибуция заключается в интерпретации поступков и действий партнера через призму собственного опыта и взглядов - причинная интерпретация на основе каузальной схемы. Чаще всего данный механизм проявляется в приписывании тех или иных характеристик (Обыденкова, 2012). Выделяют три типа подобных приписываний в зависимости от того, кому приписывается причина: личностную, объектную, обстоятельственную (Келли, 1984). Виртуальные платформы для взаимодействия, в частности социальные сети, создают широкие возможности для приписывания партнеру по взаимодействию целого спектра личностных и поведенческих характеристик, которые основываются на содержательном компоненте профиля пользователя. Таким образом, размещение на странице пользователя контента, который содержит информацию о защите окружающей среды, позволяет приписать носителю виртуального образа ряд качеств, отражающих его общественную и гражданскую позицию. Широкие возможности для приписывания также создают ситуативные комментарии в виртуальных сообществах, поддерживающих ту или иную точку зрения.

Кроме этого, механизм каузальной атрибуции срабатывает в ситуации анализа графических изображений и фотообразов, составляющих виртуальный образ. Е.В. Рягузова в ходе исследования выяснила, что во время восприятия незнакомого субъекта по фотографии, на которой очевидно прослеживаются телесные особенности, экспрессивные движения, особенности оформления внешности, происходит приписывание психологических качеств репрезентируемому образу через обработку визуальных кодов, усвоенных в ходе социализации (Рягузова, 2015).
Механизм стереотипизации в своей основе содержит устоявшиеся образы. Зачастую подобные образы относятся к обобщенным характеристикам поведения, внешности (Обыденкова, 2012). Появление стереотипа происходит из-за ограниченности прошлого опыта, что приводит к формированию выводов на основании ограниченной информации прошлого. Стереотипизация может привести к упрощению процесс познания другого субъекта и замене его образа штампом. Подобная замена может способствовать упрощению процесса восприятия и ускорению познания. С другой стороны, в ходе взаимодействия может возникнуть предубеждение, которое приведет к негативному результату восприятия образа (Баранов, 2011).

А.А. Реан разделил стереотипы на шесть групп: антропологические, этнонациональные, социальностатусные, социальноролевые, экспрессивно-эстетические, вербально-поведенческие. В ходе процесса стереотипизации возникают социальные установки, которые оказывают влияние на дальнейшие акты взаимодействия (Фомиченко, 2017). Восприятие образа личности происходит путем определения эталонов, которые способствуют интерпретации компонентов образа, состоящей в приписывании субъекту определенных качеств в соответствии с оценочными стереотипами воспринимающего (Панферов, 2009).

Механизм эмпатии направлен на эмоциональное познание другого человека (Обыденкова, 2012), эмоциональное вчувствование в субъекта (Фомиченко, 2017). Одной их основных функция эмпатии является регуляция взаимоотношений на основе необходимости оказать помощь, поддержку другим людям (Шнайдер, 2016). При этом эмпатия срабатывает при условии непосредственного восприятия переживаний другого субъекта (Гаврилова, 1981). Виртуальная среда же оказывает влияние на уровень эмпатии в межличностном взаимодействии, провоцируя проявления черствости и равнодушия. Активные пользователи социальных сетей проявляют более формальную эмпа- 
тию, эмоционально не вовлекаясь в чувства другого человека (Дмитриева, Хамзина, 2020).

Таким образом, виртуальное пространство оказывает ключевое влияние на процессы и механизмы межличностного восприятия, которое проявляется в особенностях формирования и восприятия образов личности, как ключевых трансляторов информации для налаживания успешного взаимодействия.

Материалы и методы (Methodology and methods). Исследование проводилось в реальном и виртуальном пространствах. На этапе констатирующего эксперимента для определения психологических особенностей восприятия образа личности в реальном и виртуальном пространстве в качестве психодиагностической методики был использован Тест М. Куна и Т. Макпартленда «Кто Я?» или «20 высказываний» в модификации Т.В. Румянцевой.

Данная методика представляет собой открытое не стандартизированное самоописание, которое заключается в 20 высказываниях. Главное отличие методики в модификации Т.В. Румянцевой - отсутствие жёсткой регламентации количества ответов (испытуемый может дать их больше 20, или меньше). Принципы интерпретации полученных данных остаются прежними. Методика не предполагает формализированного стимульного материала в виде вопросов, утверждений, списка качеств или картинок. Вместо этого испытуемый на чистом листе должен составить список характеристик, присущих партнеру по взаимодействию. Стимульным материалом при этом являются реальный и виртуальный образ личности.

Теоретической основой данной методики является теория М. Куна о Яконцепции, включающую изучение социальных ролей и ролевого поведения в параметрах самовосприятия. Для изучения перцептивных процессов и реализации цели исследования данная методика была модифицирована. Испытуемым предлагалось ответить на вопрос «Кто он?» и дать 20 характеристик партнеру по исследованию. Таким образом, фокус описания переместился с образа самого испытуемого, на образ партнера по взаимодействию.

В эксперименте приняло участие 90 человек, которые были разделены на 3 группы по 30 человек с равным гендерным распределением. Возраст испытуемых составлял диапазон от 17 до 22 лет. Все испытуемые являются активными пользователями социальных сетей и имеют активные наполненные аккаунты в различных социальных сетях.

Исследование проводилось в два этапа. Первая группа выступала в роли носителя реального и виртуального образов. Второй группе испытуемых необходимо было описать реальный образ партнера по взаимодействию, третьей группе - виртуальный образ испытуемых. Третья группа испытуемых отвечала на вопрос «Кто он (носитель) в виртуальном пространстве?» изучая аккаунты носителей в социальных сетях. Первая и третья группы во время эксперимента не взаимодействовали друг с другом в реальном пространстве.

Анализ результатов проводился путем контент-анализа. Статистический анализ экспериментальных данных был осуществлен с использованием программного обеспечения «SPSS 23.0» (критерий Колмогорова-Смирнова, U-критерий Манна - Уитни).

Анализ результатов исследования. Согласно условиям эксперимента, испытуемым было необходимо прописать как можно больше характеристик, которые, по их мнению, дают исчерпывающий ответ на вопрос «Кто ОН? (партнер по взаимодействию)».

Группа, оценивающая реальный образ личности, дала в общей сложности 461 характеристику своему партнеру, группа, оценивающая виртуальный образ личности 618 , что можно объяснить особенностями представления информации в профилях. Внешний информационный слой виртуального образа формируется согласно законам представления информации в социальных сетях. 
Порядок называния характеристик образов соответствует выраженности и значимости соответствующих признаков. При оценке реального образа личности порядок характеристик представлял собой список оценок согласно их доступности. В первую очередь, испытуемые давали самые очевидные, актуальные характеристики (указывали пол, возраст, социальную группу, физические характеристики). После этого, испытуемые подбирали характеристики, основываясь на предположениях, на кратких ответах партнера).

При оценке виртуального образа личности список характеристик возглавляли данные, описывающие активность в сети и при коммуникации, популярность и количество друзей/подписчиков, хобби, интересы деятельность, внешность и физические качества. Характеристики, относящиеся к описанию пола, возраста и социальной группы занимали позиции в конце списка.

Результаты исследования показали, что при восприятии реального образа 90\% испытуемых использовали прямое определение идентичностей партнера по взаимодействию (девушка, парень). При описании виртуального образа $93 \%$ характеристик представляют собой косвенное указание идентичности (студентка, волонтер, меломан).

Анализ полученных данных показал, что при межличностном восприятии можно выделить пять групп характеристик, которые воспринимаются партнерами по взаимодействию: социальные, физические, деятельные, коммуникативные и материальные характеристики, которые в свою очередь соответствуют социальному, физическому, деятельному, коммуникативному и материальному Я носителей образов, выделенных М. Куном и Т. Макпартлендом.

Таким образом, в ходе исследования удалось выделить следующие категории для анализа:

Социальные характеристики - социальные роли, статусы, принадлежность к социальным группам, прямое обозначение пола, этническая и мировоззренческая иден- тичность (девушка, студентка, дочь, татарка, христианка и т.д.).

Физические характеристики - физические данные, описание внешности, вредные привычки (привлекательная, стройная, спортивный, приятный)

Деятельное характеристики - интересы, хобби, оценка способностей к деятельности, оценка навыков и умений (любит плавать, была в Турции, прыгала с парашютом, ходит в походы).

Коммуникативные характеристики оценка характера взаимодействия с людьми, отношений с друзьями (много друзей, подписчиков, общительная, вежливая, любит общаться с людьми).

Материальное характеристики - собственность, оценка обеспеченности, отношение к внешней среде (хорошо одевается, есть собака, есть машина, состоятельный, не любит дождь, любит море).

Кроме этого, при анализе результатов восприятия виртуального образа были выявлены характеристики, которые формируют отдельную группу - виртуальные характеристики - оценка характеристик личности, которая обусловлена спецификой виртуальной среды и в частности социальными сетями (использует чужие фото, фейк, тролль, флудит, страничка совместная с парнем, спамит, постит длинные тексты (длиннопосты), собирает лайки, постоянно в сторис, блогер, тиктокер, подписана на сообщества геймеров, троллит своих подписчиков) и формирует виртуальное Я носителя образа (рис. 1, рис. 2).

С помощью критерия КолмогороваСмирнова была доказана существенность различий между распределениями двух выборок $(\mathrm{p}<0,05)$, что позволяет в качестве анализа данных выбрать непараметрические статистические критерии.

Исследование характеристик, которые были восприняты испытуемыми во время проведения эксперимента позволило сделать выводы о наличии статистически достоверных различий в выраженности показателей по категориям физического Я (Uэмп $\leq \mathrm{U \kappa p,} \mathrm{p} \leq 0,05)$, деятельного Я (Uэмп $\leq$ 
Uкр, $\mathrm{p} \leq 0,05)$, коммуникативного Я (Uэмп $\leq$ Uкр, $\mathrm{p} \leq 0,05)$. Анализ сравнения категорий социального Я и материального Я не пока- зал статистически достоверных различий (Uэмп $\geq$ Uкр, $\mathrm{p} \geq 0,05$ ) (таблица).

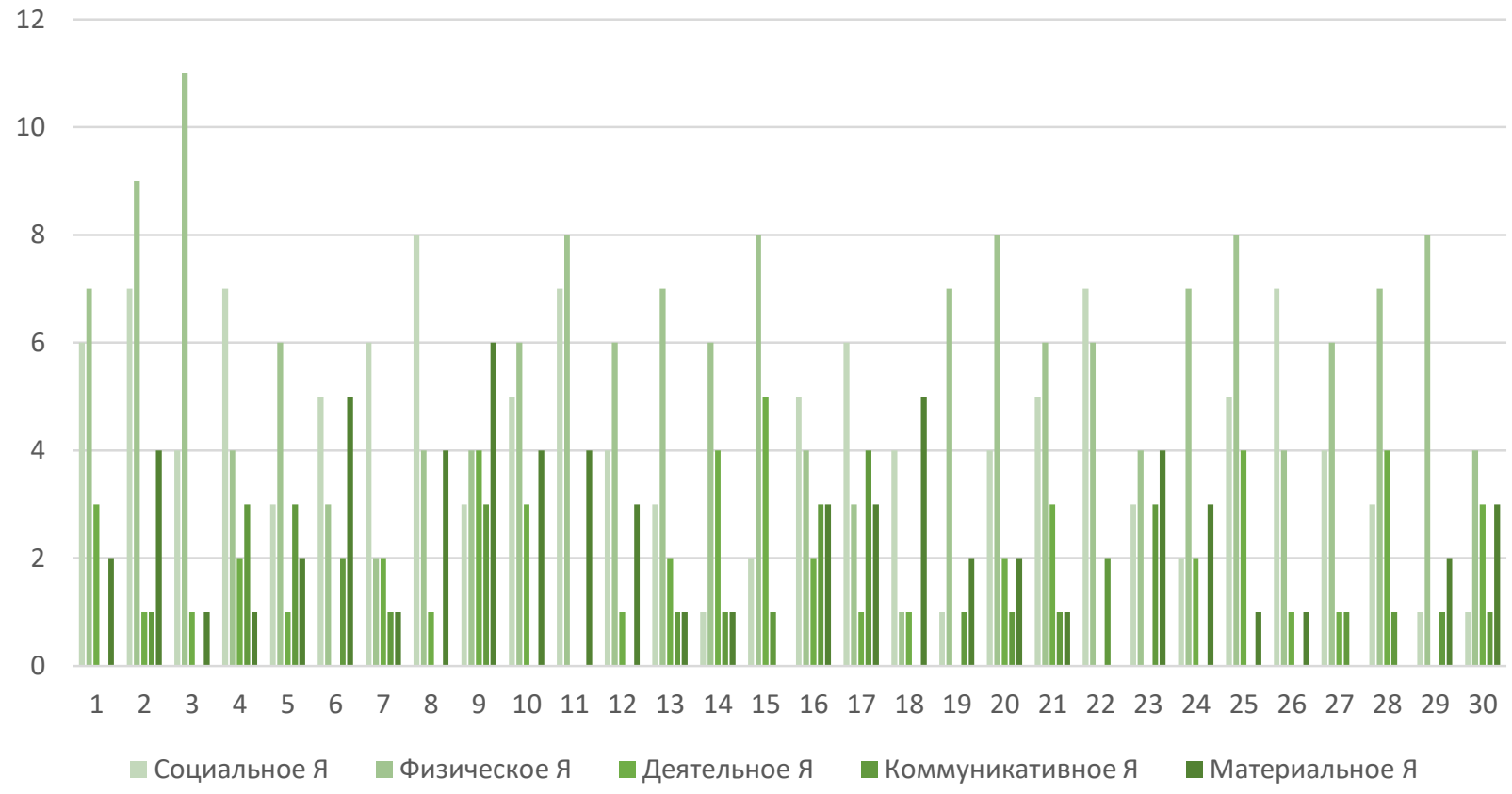

Рис. 1 Количественное распределение характеристик, данных при восприятии реальных образов

Fig. 1 Quantitative distribution of characteristics given in the perception of real images

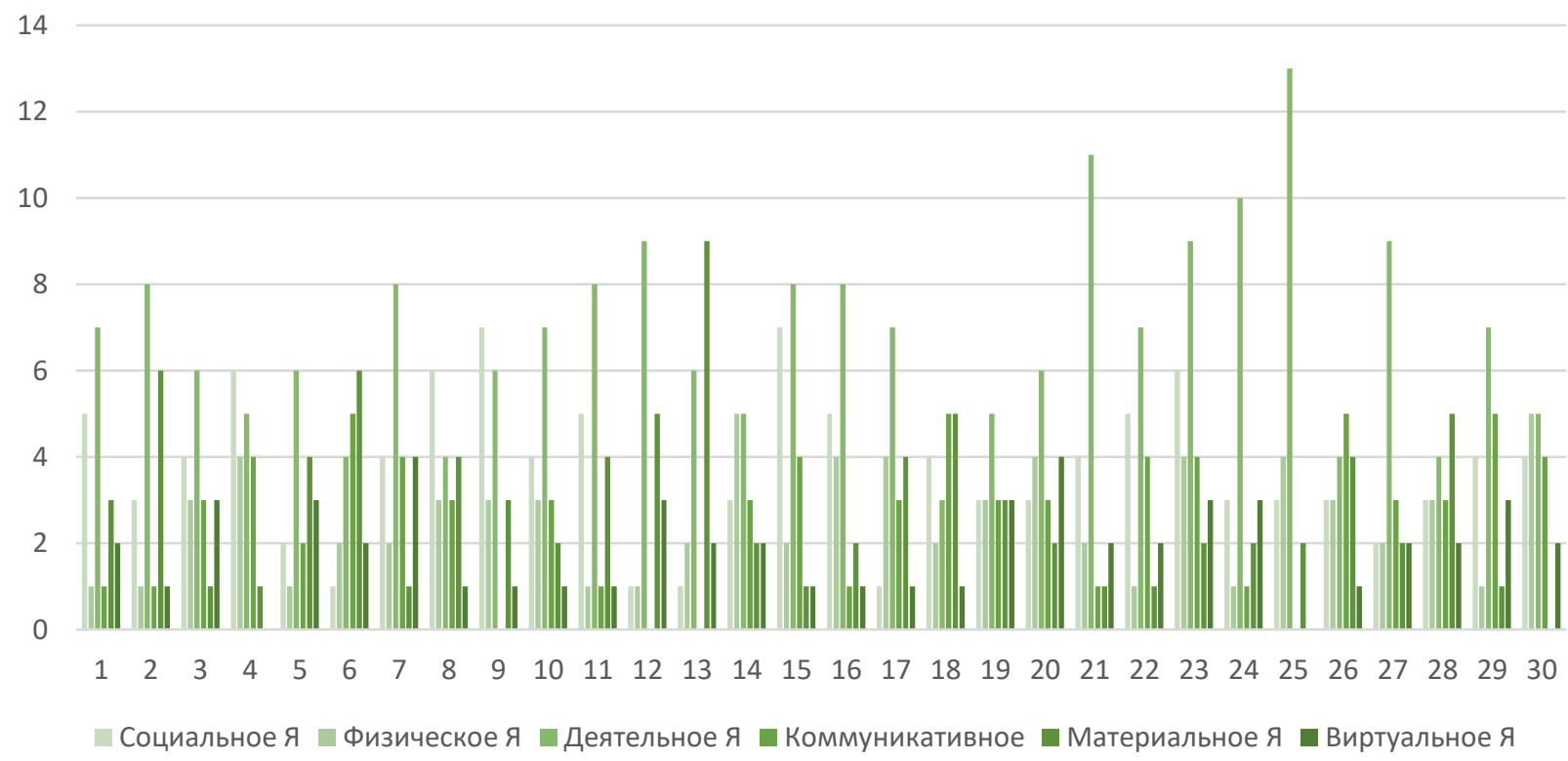

Рис. 2. Количественное распределение характеристик, данных при восприятии виртуальных образов

Fig. 2. Quantitative distribution of characteristics given in the perception of virtual images 
Таблица

Результаты сравнительного анализа характеристик виртуального и реального образов в процессе межличностного восприятия

Table

\begin{abstract}
Results of comparative analysis of the characteristics of virtual and real images in the process of interpersonal perception
\end{abstract}

\begin{tabular}{|l|c|c|c|c|}
\hline \multirow{2}{*}{$\begin{array}{c}\text { Категория } \\
\text { характеристик }\end{array}$} & \multicolumn{2}{|c|}{ Средние значения } & $\begin{array}{c}\text { U- } \\
\text { сритерий } \\
\text { Реальый } \\
\text { образ }\end{array}$ & $\begin{array}{c}\text { Виртуальный } \\
\text { образ } \\
\text { Уинень } \\
\text { стической } \\
\text { значимости (p) }\end{array}$ \\
\hline Социальное Я & 4,30 & 3,73 & 375,000 & 0,261 \\
\hline Физическое Я & 5,80 & 2,57 & 102,500 & 0,000 \\
\hline Деятельное Я & 1,80 & 6,83 & 21,000 & 0,000 \\
\hline Коммуникативное Я & 1,17 & 2,63 & 225,500 & 0,001 \\
\hline Материальное Я & 2,30 & 2,93 & 372,000 & 0,241 \\
\hline
\end{tabular}

Анализ полученных характеристик позволяет сделать вывод о незначительных различиях в восприятии социального компонента реального и виртуального образов. Социальное Я содержит в себе характеристики, которые, в первую очередь, отражают взаимоотношения субъекта и общества и заключается в интерактивном статусе, положении и роли личности в социуме. Виртуальный и реальный образ личности являются трансляторами данных характеристик. Социальный компонент образа личности отражает положение субъекта в социуме, которое в свою очередь влияет на всю активность человека и в том числе на межличностное взаимодействие. Социальные роли, статусы и положения усваиваются личностью во время социализации, закрепляются в когнитивных структурах и функциональных моделях личности, с помощью которых он выстраивает свое взаимодействие с обществом. Незначительность различий объясняется равномерным объемом сигналов и информации, представленных в реальном и виртуальном образах личности.

Физический компонент образа личности согласно данным исследования наиболее выражен в реальном образе личности.
Данный результат можно объяснить тем, что характеристики физического Я в реальном пространстве являются наиболее доступными, нежели в виртуальном пространстве. Информация о внешнем облике носителя в виртуальном пространстве содержится в фото и видеообразах и в связи со спецификой структуры представления информации в профиле пользователя не является основой для образа. Физическое, телесное присутствие виртуальной личности в цифровом пространстве долгое время отсутствовали или имели искаженные варианты (ролевые игры-стратегии с возможностью создания аватара). Данная ситуация изменилась после появления Instagram, селфи (фото самого себя) и сторис (небольшие видеоролики, снятые в настоящее время по принципу здесь и сейчас). Новые виртуальные площадки и инструменты, таким образом, создают возможности в будущем для формирования виртуальной телесности пользователей и расширения диапазона физического компонента в виртуальном образе личности. Немаловажную роль в данном процессе играет дополненная реальность, которая расширяет виртуальную телесность. 
Деятельное Я представлено в более полном объеме в виртуальном пространстве. Деятельный компонент образа личности содержит в себе интересы, занятия, увлечения личности и их оценку. Доступность информации о деятельном Я обусловлена особенностями структурирования композиции виртуального образа в Интернете. Большинство виртуальных платформ предусматривают авторизацию своих пользователей путем заполнения анкеты. Социальные сети позволяют ознакомится с интересами и взглядами пользователя путем изучения описательной части профиля и сложить свое представление о воспринимаемом пользователе.

Коммуникативный компонент образа личности по данным исследования в наибольшей степени воспринимается в виртуальном пространстве. Коммуникативное Я отражает личность как субъекта общения с другими людьми. Подобный результат объясняется тем, что для того, чтобы сделать выводы о коммуникативной стороне образа в реальном пространстве необходимо некоторое время для общения. Виртуальное же пространство позволяет сделать выводы о коммуникативном Я пользователя, основываясь лишь на количестве друзей и подписчиков, рейтинге профиля, манере общения в комментариях, активности в сторис.

Восприятие материального компонента образа личности, согласно проведенному исследованию, не имеет существенных различий в реальном и виртуальном пространствах. Это объясняется, прежде всего, доступностью и простотой сигналов-стимулов, отвечающих за данный компонент образа.

Кроме это, важным результатом данного исследования стало выделение отдельного компонента образа личности, присущего только виртуальному пространству. Виртуальное Я включает в себя характеристики, которые присущи виртуальному образу личности и находят свое проявление в виртуальной активности, в специфичности формирования данного компонента образа личности (рис. 3). Виртуальное Я определяет степень принятия виртуального мира как пространства для существования (жизненного пространства), идентификацию себя как представителя сетевой культуры.

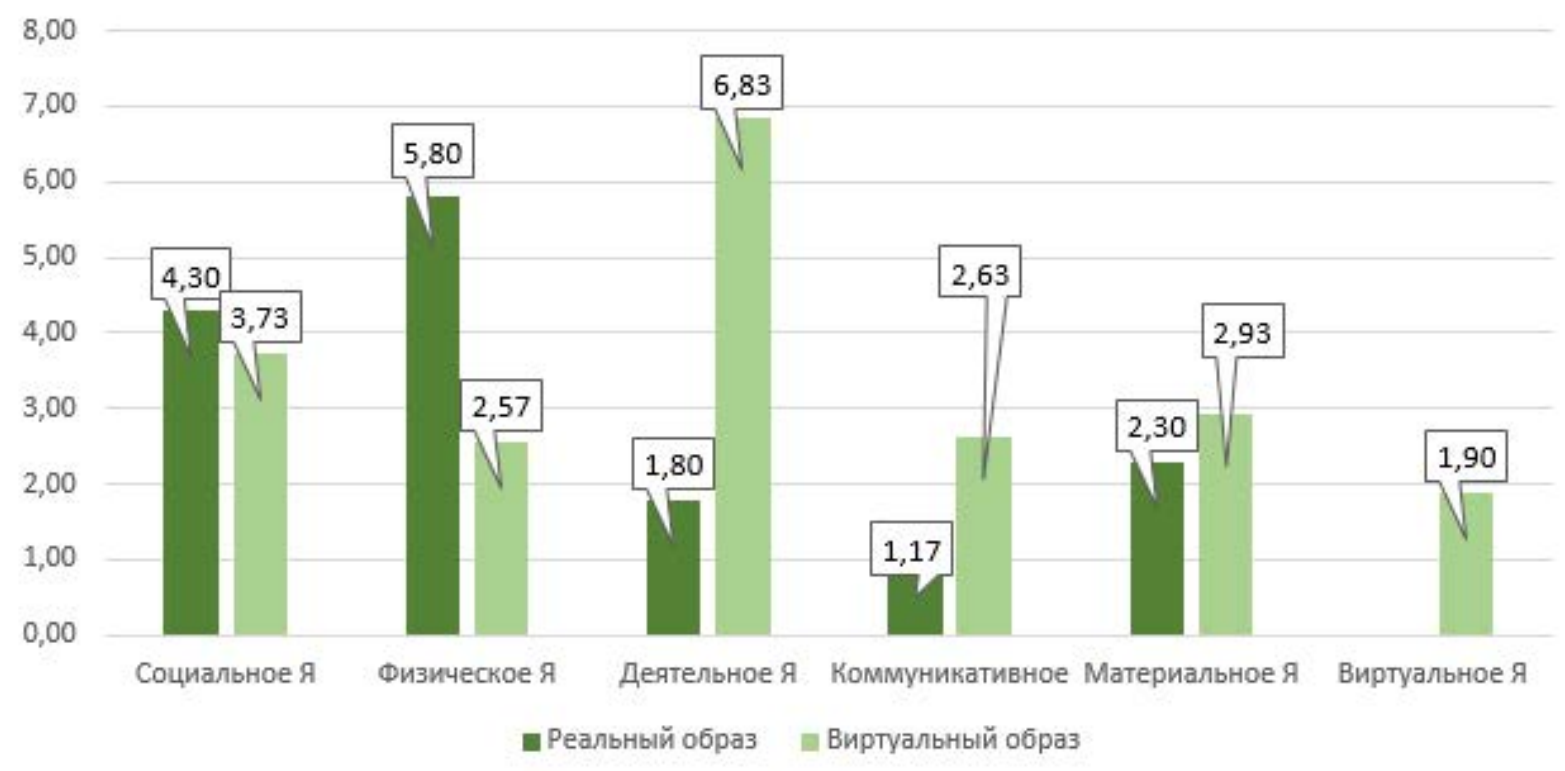

Рис. 3. Особенности выраженности компонентов реального и виртуального образов личности в процессе социальной перцепции

Fig. 3. Peculiarities of expression of components of real and virtual images of personality in the process of social perception 
Заключение (Conclusions). Виртуальное пространство выстраивает совершенно новые законы межличностного взаимодействия, затрагивая также процессы социальной перцепции, которые являются неотъемлемой их частью. Наглядно-образное отражение субъектами взаимодействия друг друга в виртуальном пространстве приобретает ряд характерных черт, которые в значительной степени влияют на результат и эффективность социального взаимодействия и социального познания.

Анализ и интерпретация виртуального образа происходит путем непосредственного, наглядно-образного, чувственного отражения сигналов-символов, которые формируют образ личности. Данные сигналы символы преобразуются путем обобщения и отбора информации с помощью когнитивных процессов выстраивая общую картину внешнего облика и характеристик выразительного поведения партнера по взаимодействию, которые формируют реальный и виртуальный образы личности.

Данное исследование позволило сделать ряд следующих заключений:

- присутствует существенная связь между процессами социального восприятия субъектами друг друга и виртуальным образом личности, как носителем информации о партнере по взаимодействию, которая обусловлена все большим преобладанием виртуального взаимодействия над реальным;

- в виртуальном пространстве процессы и механизмы, связанные с социальной перцепцией, имеют ряд особенностей, которые связаны со спецификой форм взаимодействия, способами структурирования и представления образа личности;

- виртуальный образ личности занимает важное место в процессах социального взаимодействия в современном мире;

- виртуальный образ личности содержит в себе компоненты, которые характерны и реальному образу, однако степень доступности и содержательности данных компонентов при социальной перцепции имеет ряд существенных отличий;
- виртуальный образ личности в отличии от реального содержит в себе компонент, который обусловлен спецификой виртуального пространства и содержит в себе слой информации, описывающей активность и особенности виртуального Я пользователя.

Теоретическая значимость данного исследования заключается в рассмотрении феномена «виртуальный образ личности» как конструкции, включающей в себя информацию о личности и способствующей успешному взаимодействию людей в современном информационном мире, а также в выявлении особенностей межличностного восприятия в виртуальном пространстве. Дальнейшее изучение особенностей данного процесса позволят более детально рассмотреть «виртуальный образ личности», а также выделить его психологические характеристики и закономерности формирования.

\section{Список литературы}

Андреева Г.М. Социальная психология. М.: Аспект Пресс, 2001. 384 с.

Баранов А.Б. Социальная перцепция в условиях межличностного и текстового взаимодействия // Психологические и педагогические науки. Всероссийский журнал научных публикаций. 2011. С. 46-48.

Бодалев А.А. Восприятие человека человеком. Ленинград: Изд-во Ленинградского университета, 1965. $121 \mathrm{c.}$

Войскунский А. Социальная перцепция в социальных сетях // Вестник Московского университета. Серия 14. Психология. 2014. №2. C. 90-104.

Гаврилова Т.П. Анализ эмпатийных переживаний младших школьников и младших подростков // Психология межличностного познания / под ред. А. А. Бодалева, Акад. пед. наук СССР. М.: Педагогика. 1981. С. 122-139.

Гозман Л.Я. Психология эмоциональных отношений. М.: Изд-во МГУ, 1987. 174 с.

Дмитриева Л.Г., Хамзина Д.В. Особенности проявления эмпатии у студентовпользователей социальных сетей // Вестник Московского государственного лингвистического университета. Образование и педагогические науки. 2020. № 1 (834). С.175-187.

Келли Г. Процесс каузальной атрибуции. Современная зарубежная социальная психоло- 
гия: тексты. / под общ. ред. Г.М. Андреевой, Н.Н. Богомоловой, Л.А. Петровской. М.: Изд. Московского университета, 1984. С. 127-137.

Обыденкова В.К. Межличностное восприятие в контексте киберсоциализации человека в социальных сетях интернет-среды // Сборник докладов V Межвузовской конференции «Экспериментальные исследования молодых ученых по результатам исследований в области психологии, педагогики, социокультурной антропологии». М.: Издательский отдел Центра исследовательских технологий REDU. 2012. C. $400-404$.

Панферов В.Н. Когнитивные эталоны и стереотипы взаимопознания людей // Вопросы психологии. 1982. № 5. С. 139-141.

Панферов В.Н. Теоретические следствия из опыта познания человека человеком // Вестник Санкт-Петербургского университета. Cер. 12. 2009. Вып. 3. Ч. ІІ. С. 228-237.

Панферов В.Н. Методологические последствия изучения социальной перцепции // Методология и история психологии. 2009. Том 4. Вып. 3. С. 142-153.

Расина Э.О. Концепт «виртуальный образ личности» в понятийном поле психологии: теоретико-методологический дискурс // Ученые записки Крымского инженерно-педагогического университета. Серия: Педагогика. Психология. 2019. № 2 (16). С. 66-69.

Рягузова Е.В. Социокультурная обусловленность восприятия внешности незнакомого другого // Изв. Сарат. ун-та. Акмеология образования. Психология развития. 2015. Т. 4, вып. 2(14) С. 166-169.

Фомиченко А.С. Особенности социальной перцепции // Вестник Оренбургского государственного университета. 2017. № 2 (202). C. 17-21.

Шнайдер М. И. Эмпатия как форма отражения другого // Гуманизация образования. 2016. № 2. C. 60-65.

Folkes V.S. "Forming relationships and the matching hypothesis" // Personality and Social Psychology Bulletin, 1982. Vol. 8. P. 631-636.

Miller R., Perlman D., Brehm S. Intimate Relationships, 2006, New York: McGraw-Hill, USA.

Moreland Richard L., Beach Scott R. "Exposure effects in the classroom: The development of affinity among students" // Journal of Experimental Social Psychology: journal. May 1992. Vol. 28. P. 255-276.
Turkle Sh. The second self: computers and the human spirit, 20th anniversary ed. The MIT Press, Twentieth Anniversary edition. 2015.

Walster E., Walster G.W., Berscheid E., Dion K. "Physical attractiveness and dating choice: A test of the matching hypothesis" // Journal of Experimental Social Psychology: journal. March, 1971. Vol. 7 (2). P. 161-173.

Wu Y.J., Chang Wei-Hung, Yuan ChihHung, "Do Facebook profile pictures reflect user's personality?" // Computers in Human Behavior. October, 2015. Vol. 51, Part B. P. 880-889.

\section{References}

Andreeva, G.M. (2001), Sotsial'naya psikhologiya [Social psychology], Aspekt Press, Moscow, Russia.

Baranov, A.B. (2011), "Social perception in the context of interpersonal and textual interaction", Pskihologicheskie i pedagogicheskie nauki. Vserossijskij zhurnal nauchnyh publikatsij, 46-48. (In Russian).

Bodalev, A.A. (1982), Vospriyatie $i$ ponimanie cheloveka chelovekom [Perception and understanding of man by man], Moscow University Press, Moscow, Russia.

Vojskunskij, A. (2014), "Social perception in social networks", Vestnik Moskovskogo universiteta. Serija 14, Psikhologija, 2, 90-104. (In Russian).

Gavrilova, T.P. (1981), "Analysis of younger schoolchildren and younger adolescents' empathic experiences", Psikhologija mezhlichnostnogo poznanija. Akad. ped. nauk SSSR, 122-139. (In Russian).

Gozman, L.Ja. (1987), Psikhologija emotsional'nyh otnoshenij [The psychology of emotional relationships], Izd-vo MGU, Moscow, Russia.

Dmitrieva, L.G. and Hamzina, D.V. (2020), "Features of the empathy manifestation among students - social networks users", Vestnik Moskovskogo gosudarstvennogo lingvisticheskogo universiteta. Obrazovanie $i$ pedagogicheskie nauki, 1 (834), 175-187. (In Russian).

Kelli G. (1984), Protsess kauzal'noy atributsii. Sovremennaya zarubezhnaya sotsial'naya psikhologiya: teksty [The process of causal attribution. Contemporary foreign social psychology: texts], Izd. Moskovskogo universiteta, Moscow, Russia.

Obydenkova V.K. (2012), "Interpersonal perception in the context of human cyber socialization in social networks of the Internet environ- 
ment", Sbornik dokladov v Mezhvuzovskoj konferencii "Eksperimental'nye issledovanija molodyh uchenyh po rezul'tatam issledovanij $v$ oblasti psikhologii, pedagogiki, sotsiokul'turnoj antropologii”. 400-404. (In Russian).

Panferov V.N. (1982), "Cognitive standards and stereotypes of mutual understanding of people", Voprosy psihologii. 5. 139-141. (In Russian).

Panferov V. N. (2009), "Theoretical consequences from the experience of human cognition by man", Vestnik Sankt-Peterburgskogo universiteta, 12 (3), Ch. II, 228-237. (In Russian).

Panferov V.N. (2009), "Methodological implications of studying social perception" Metodologija $i$ istorija psikhologii, 4 (3), 142-153. (In Russian).

Rasina Je.O. (2019), "The concept of «virtual image of the person» in the conceptual field of psychology: the theoretical and methodological discourse" Uchenye zapiski Krymskogo inzhenernopedagogicheskogo universiteta. Serija: Pedagogika. Psikhologija, 2 (16), 66-69. (In Russian).

Ryaguzova E.V. (2015), "Sociocultural conditioning of the appearance perception of an unfamiliar other" Izv. Sarat. un-ta. Akmeologija obrazovanija. Psikhologija razvitija, 4, 2(14), 166-169. (In Russian).

Fomichenko A.S. (2017), "Social perception features", Vestnik Orenburgskogo gosudarstvennogo universiteta, 2 (202), 17-21. (In Russian).

Shnajder M.I. 2016. "Empathy as a form of the others reflection", Gumanizacija obrazovanija, 2, 60-65. (In Russian).

Folkes V.S. (1982). Forming relationships and the matching hypothesis.Personality and Social Psychology Bulletin, 8, 631-636.

Miller, R., Perlman, D. and Brehm, S (2006). Intimate Relationships. New York: McGraw-Hill. (USA).
Moreland, Richard L. and Beach, Scott R. (1992). Exposure effects in the classroom: The development of affinity among students. Journal of Experimental Social Psychology: journal, May, 28, 255-276.

Turkle, Sherry. The second self: computers and the human spirit / Sherry Turkle. 20th anniversary ed. The MIT Press; Twentieth Anniversary edition. (USA).

Walster, Elaine, G. William Walster, Ellen Berscheid and Karen Dion (1971).'Physical attractiveness and dating choice: A test of the matching hypothesis" Journal of Experimental Social Psychology, March, 7 (2), 173.

$\mathrm{Wu}$, Y.J., Chang, Wei-Hung and Yuan, Chih-Hung (2015), "Do Facebook profile pictures reflect user's personality?" Computers in Human Behavior. October 51, (Part B), 880-889.

Информация о конфликте интересов: автор не имеет конфликта интересов для декларации. Conflicts of Interest: the author has no conflict of interests to declare.

\section{Данные автора:}

Расина Эвелина Османовна, преподаватель кафедры психологии, факультета психологии и педагогического образования, Крымский инженерно-педагогический университет имени Февзи Якубова.

\section{About the author: \\ Evelina O. Rasina, Lecturer, Department of Psy- chology, Faculty of Psychology and Pedagogical Education, Fevzi Yakubov Crimean Engineering and Pedagogical University.}

